\title{
NUMERICAL INVESTIGATION OF FLUID FLOW AND HEAT TRANSFER AROUND A CIRCULAR CYLINDER UTILIZING NANOFLUID FOR DIFFERENT THERMAL BOUNDARY CONDITION IN THE STEADY REGIME
}

\author{
R. Bouakkaz ${ }^{1 *}$, F. Salhi ${ }^{2}$, Y. Khelili ${ }^{3}$, M. Ouazzazi ${ }^{4}, K$. Talbi $^{4}$ \\ ${ }^{1}$ Military academy of Cherchell, Tipaza, Algeria \\ ${ }^{2}$ Département de Génie Mécanique, université Mouloud Mammeri \\ Tizi ouzou, Algeria \\ ${ }^{3}$ Department of Mechanical Engineering, University Saad Dahlab, \\ Blida 1, Algeria \\ ${ }^{4}$ Département de Génie Mécanique, université Constantine 1, \\ Constantine, Algeria
}

Received 26.05.2017

Accepted 24.06.2017

\begin{abstract}
In this work, steady flow-field and heat transfer through a copper-water nanofluid around a circular cylinder, under the influence of both the standard thermal boundary conditions i.e. uniform heat flux (UHF) and constant wall temperature (CWT) was investigated numerically by using a finite-volume method for Reynolds numbers of 10 to 40 . Furthermore, the range of nanoparticle volume fractions $(\varphi)$ considered is $0 \leq \varphi \leq 5 \%$. The variation of the local and the average Nusselt numbers with Reynolds number, and volume fractions are presented for the range of conditions. The average Nusselt number is found to increase with increasing the nanoparticle volume fractions.
\end{abstract}

Keywords: Copper nanoparticles; heat transfer; circular cylinder; steady regime.

\section{Introduction}

Fluid flow and heat transfer around bluff body has been a subject of great interest for researchers due to its high applicability in many industrial developments. The applications may include heat exchangers [1,2], cylindrical cooling devices in plastics and glass industries, food processing and nuclear power plants. In these flows, the results depend on the Reynolds number (Re), expressed as:

\footnotetext{
* Corresponding author: Rafik Bouakkaz: r.bouakkaz@gmail.com
} 


$$
\operatorname{Re}=\frac{U \infty D}{v}
$$

The authors of the work [3] using standard boundary conditions namely constant wall temperature (CWT) studied the local and average heat transfer characteristics around a circular cylinder for the Re number range of $2 \cdot 10^{3}$ to $9 \cdot 10^{4}$ and Pr number range of 0.7 to 176 . Three regions of flow: laminar boundary layer, reattachment of shear layer and periodic vortex regions was indicated around the cylinder for subcritical flow. Further, they developed an empirical correlation for predicting the overall heat transfer from these three regions. Also, the authors [4] using uniform dissipating heat flux boundary conditions (UHF) investigated numerically the free stream flow and forced convection heat transfer across a rotating cylinder for Reynolds numbers of 10 to 45 and $0.7<\operatorname{Pr}<400$. Their results show that the heat transfer is increase with an increase in Re and/or Pr numbers.

The flow and heat transfer over an isothermal across a rotating cylinder in the range $0 \leq \alpha \leq 6$ with Re number varying from 20 to 160 was studied in literature [5-7]. In depth analysis, it was revealed that the rotation can be used as a drag reduction and heat transfer suppression technique. Further, authors [8] studied numerically the free stream flow and forced convection heat transfer across a rotating cylinder, dissipating heat flux for Reynolds numbers of 20 to 160 and a Prandtl number of 0.7 . Their results show that, at higher rotational velocity, the Nusselt number is almost independent of Reynolds number and the thermal boundary conditions.

In past studies, the fluids used have a low value of thermal conductivity, which limits heat transfer. For this reason, there are several methods to improve the heat transfer characteristics, which consist in adding high conducting solid particles in the base fluid. The resulting fluid is called "nanofluid" [9-11]. The steady flow-field and heat transfer through a copper-water nanofluid around circular cylinder was numerically simulated [12]. The values of vorticity, pressure coefficient, and recirculation length are increased by the addition of nanoparticles into base fluid. Subsequently, [13] they examined the effect of heat treatment process with a new cooling medium (nanofluid), which contains water with $\mathrm{Cu}, \mathrm{Ag}$, or $\mathrm{Al}_{2} \mathrm{O}_{3}$ particles, on heat transfer characteristics and mechanical properties of an unsteady continuous moving cylinder in the thermal forces. They reported that the $\mathrm{Al}_{2} \mathrm{O}_{3}$ nanofluid is the best type of nanofluid for improving the mechanical properties of the surface (increase the heat flux). This nanofluid is also the best type for decreasing the surface shear stress. Recently, authors [14] have focused on numerical study of heat transfer phenomena over an isothermal cylinder for low Reynolds number flow of nanofluid. They have shown that at a given Nusselt number, drag coefficient, recirculation length, and pressure coefficient increase by increasing the volume fraction of nanoparticles. On the other hand, authors [15] have studied the momentum and forced convection heat transfer for a laminar and steady free stream flow of nanofluids past a square cylinder. Different nanofluids consisting of $\mathrm{Al}_{2} \mathrm{O}_{3}$ and $\mathrm{CuO}$ with base fluids of water and ethylene glycol, 60:40 (by mass), were selected to evaluate their superiority over conventional fluids. They showed that for any given particle diameter there is an optimum value of particle concentration that results in the highest heat transfer coefficient. The fluid flow and heat transfer around a square cylinder utilizing $\mathrm{Al}_{2} \mathrm{O}_{3}-$ $\mathrm{H}_{2} \mathrm{O}$ nanofluid over low Reynolds numbers varied within the range of 1 to 40 and the 
volume fraction of nanoparticles $(\varphi)$ is varied within the range of $0<\varphi<0.05$. was investigated [16]. It was found that the increasing the nanoparticles volume fractions augments the drag coefficient. Moreover, pressure coefficient increases by increasing the solid volume fraction for sides where pressure gradient is inverse but for sides where the pressure gradient is favourable the pressure coefficient decreases. The present investigation had been motivated by increased interest and research in potential improvements in heat transfer characteristics using nanofluids. Effort has been made to investigate numerically the steady flow of nanofluid and heat transfer characteristics under the influence of both the standard thermal for a range of Reynolds numbers $(10 \leq$ $\operatorname{Re} \leq 40$ ), and particle volumetric concentrations ranging from $0 \%$ to $5 \%$.

\section{Problem statement, governing equations, and boundary conditions}

The system here consists of a 2D infinitely long circular cylinder having a diameter $D_{t}$. It is exposed to a constant free stream velocity of $U_{\infty}$ at a uniform temperature of $T_{\infty}$ at the inlet. The nanoparticles are assumed to be uniform shape and size. In addition, we have assumed that nanoparticles are in thermal equilibrium state and flowing at the same velocity. Flow configuration is shown in Figure 1.

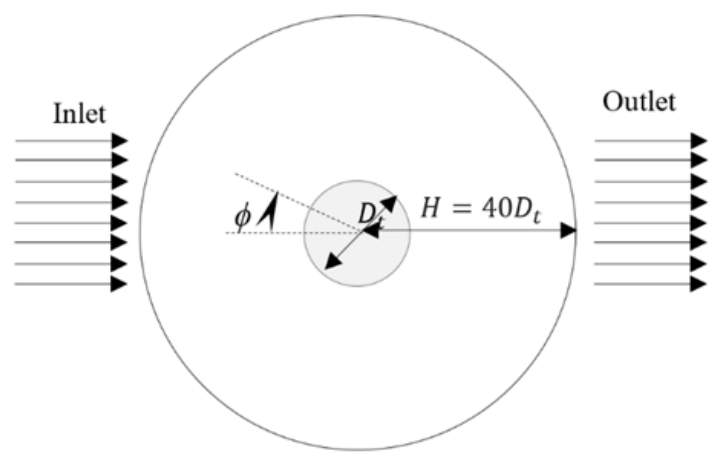

Fig. 1. Schematic of the unconfined flow past a circular cylinder

Governing equations and boundary conditions

The governing partial differential equations here are the Navier-Stokes and energy equations in two dimensions and steady state nanofluid flow around a circular cylinder are given blow:

$$
\frac{\partial U}{\partial X}+\frac{\partial V}{\partial Y}=0
$$

$U \frac{\partial U}{\partial X}+V \frac{\partial U}{\partial Y}=-\frac{\partial P}{\partial X}+\frac{1}{\operatorname{Re}} \frac{v_{n f}}{v_{f}}\left(\frac{\partial^{2} U}{\partial X^{2}}+\frac{\partial^{2} U}{\partial Y^{2}}\right)$

$$
U \frac{\partial V}{\partial X}+V \frac{\partial V}{\partial Y}=-\frac{\partial P}{\partial Y}+\frac{1}{\operatorname{Re}} \frac{v_{n f}}{v_{f}}\left(\frac{\partial^{2} V}{\partial X^{2}}+\frac{\partial^{2} V}{\partial Y^{2}}\right)
$$


$U \frac{\partial \theta}{\partial X}+V \frac{\partial \theta}{\partial Y}=\frac{1}{\operatorname{Re} \operatorname{Pr}} \frac{\alpha_{n f}}{\alpha_{f}}\left(\frac{\partial^{2} \theta}{\partial X^{2}}+\frac{\partial^{2} \theta}{\partial Y^{2}}\right)$

with the following correlations:

$U=\frac{u}{U_{\infty}} ; V=\frac{v}{U_{\infty}} ; X=\frac{x}{D_{t}} ; Y=\frac{y}{D_{t}} ; P=\frac{p}{\rho_{n f} U_{\infty}^{2}} ; \operatorname{Pr}=\frac{v_{f}}{\alpha_{f}} ; \operatorname{Re}=\frac{U_{\infty} D_{t}}{v_{f}}$,

where $\mathrm{U}$ and $\mathrm{V}$ are the velocity components along $\mathrm{X}$ and $\mathrm{Y}$ axes, $\mathrm{T}$ denotes the temperature, $\mathrm{P}$ is the pressure, $\rho$ is the density, $\mu$ the dynamic viscosity. The subscript $n f$ stands for nanofluid, the subscript $f$ stands for base fluid and the subscript $s$ stands for solid nanoparticles. The thermophysical properties taken from literature [12], for the base fluid and copper oxide (at $300 \mathrm{~K}$ ) are shown in Table 1.

Table 1. Thermo-physical properties of the base fluid and the Cu nanoparticles

\begin{tabular}{lcc}
\hline Property & Water & Copper \\
\hline$C_{p}\left(\mathrm{~J} \cdot \mathrm{kg}^{-1} \cdot \mathrm{K}^{-1}\right)$ & 4179 & 385 \\
$\rho\left(\mathrm{kg} \cdot \mathrm{m}^{-3}\right)$ & 997.1 & 8.933 \\
$\mathrm{k}\left(\mathrm{W} \cdot \mathrm{m}^{-1} \cdot \mathrm{K}\right)$ & 0.613 & 401 \\
\hline
\end{tabular}

The effective density, the thermal diffusivity, the heat capacitance, the effective dynamic viscosity and the effective thermal conductivity of the nanofluid are calculated using the following expressions:

$$
\begin{aligned}
& \rho_{n f}=(1-\phi) \cdot \rho_{f}+\phi \cdot \rho_{s} \\
& \left(\rho \cdot C_{p}\right)_{n f}=(1-\phi) \cdot\left(\rho \cdot C_{p}\right)_{f}+\phi \cdot\left(\rho \cdot C_{p}\right)_{s} \\
& \alpha_{n f}=\frac{k_{n f}}{\left(\rho \cdot C_{p}\right)_{n f}} \\
& \mu_{n f}=\frac{\mu_{f}}{(1-\varphi)^{2.5}} \\
& k_{n f}=k_{b f}\left[\frac{\left(k_{s}+2 k_{f}\right)-2 \varphi\left(k_{f}-k_{s}\right)}{\left(k_{s}+2 k_{f}\right)+\varphi\left(k_{f}-k_{s}\right)}\right]
\end{aligned}
$$

where $\varphi$ is the solid volume fraction. 
Boundary conditions

The dimensionless boundary conditions for the flow across a rotating circular cylinder can be written as (Figure1): The left-hand arc is the inflow section or upstream section, where there is a Dirichlet-type boundary condition for the Cartesian velocity components:

$$
V=0 \text { and } \theta=0
$$

The right-hand arc represents the outflow boundary, where it is considered that the diffusion flux in the direction normal to the exit surface is zero for all variables:

$$
\left(\frac{\partial U}{\partial X}=\frac{\partial V}{\partial X}=\frac{\partial \theta}{\partial X}=0\right)
$$

Finally, the dimensionless peripheral or tangential velocity is prescribed on the surface of the cylinder, along with a no-slip boundary condition:

$$
(U=0 ; V=0), \frac{\partial \theta}{\partial n_{s}}=-1(\text { for } U H F) ; \theta=1(\text { for } C W T)
$$

Here, in case of CWT, non-dimensional temperature is given as $\theta=\frac{T-T_{\infty}}{T_{W}-T_{\infty}}$ while for UHF, the non-dimensional temperature is given as $\theta=\frac{T-T_{\infty}}{\left(q_{w} D / k\right)}$, where ns is the normal unit direction vector away from the cylinder surface.

\section{Numerical details}

The steady, laminar, segregated solver was employed here to solve the incompressible flow on the collocated grid arrangement. Semi implicit method for the pressure linked equations (SIMPLE) was used to solve Navier-Stokes and energy equations for above noted boundary conditions. Second order upwind scheme is used to discretize the convective terms of momentum equations, whereas the diffusive terms are discretized by central difference method. A convergence criterion of $10^{-8}$ is used for continuity, and $\mathrm{x}-\mathrm{y}$ components of momentum equations; for energy equation, the criteria of convergence was $10^{-10}$.

Table 2. Effect of grid number on averaged Nusselt number at $R e=40$, $\operatorname{Pr}=4.76(\varphi=0.05)$

\begin{tabular}{lcccc}
\hline Mesh & Cells & $\mathrm{Nt}$ & $\mathrm{h}_{\mathrm{Dt}} / \mathrm{D}_{\mathrm{t}}$ & $\overline{N u}$ \\
\hline M1 & 32000 & 160 & 0.0015 & 9.3447 \\
M2 & 40000 & 200 & 0.0010 & 9.3766 \\
M3 & 50000 & 250 & 0.0010 & 9.3688 \\
\hline
\end{tabular}

\section{Domain independence study}

The mesh used for all the two-dimensional computations consisted of 40000 quadrilateral cells and 40200 nodes. The cylinder (of diameter $\mathrm{D}_{\mathrm{t}}$ ) resides in a computational domain whose outer edges are located at a distance of $\mathrm{H}$ from the center 
of the cylinder (Figure 1). There are $\mathrm{N}_{\mathrm{t}}$ points in the circumferential direction on the cylinder surface and the radial thickness of the first layer of cells (i.e., cells attached to the wall) is $h_{D t}$. In this study, following literature data $[5,6]$, the computational domain extends 40 times the diameter of the cylinder in all directions. The grids sensitivity analysis is performed for $\operatorname{Re}=40$ and $\varphi=0.05$. Table 2 lists the details for the meshes that were employed. As a Regarding the influence of the number of grid points on the average Nusselt number on the wall of cylinder, it was decided to carry out the computations in this work with mesh M2.

\section{Results and discussion}

\section{Comparison with other results}

The first step was to validate the problem set-up, the choice of numerical methods and mesh attributes by comparing results from our numerical simulations with results obtained from the literature. The outcomes included in the comparison were the mean Nusselt number.

Table 3. Comparison of Nu number computed in the present study with literature data

$$
(\operatorname{Pr}=0.7)
$$

\begin{tabular}{|c|c|c|c|c|}
\hline \multirow{3}{*}{ UHF } & \multicolumn{2}{|c|}{ Paramane et al. [6] } & \multirow{2}{*}{$\begin{array}{c}\text { Present study } \\
2.7382\end{array}$} & \multirow{2}{*}{$\frac{\text { Relative error }(\%)}{0.43}$} \\
\hline & $\operatorname{Re}=20$ & 2.7499 & & \\
\hline & $\mathrm{Re}=40$ & 3.7499 & 3.7618 & 0.32 \\
\hline \multirow{3}{*}{ CWT } & Parama & et al. [8] & Present study & Relative error $(\%)$ \\
\hline & $\mathrm{Re}=20$ & 2.4092 & 2.4189 & 0.40 \\
\hline & $\mathrm{Re}=40$ & 3.2496 & 3.2465 & 0.10 \\
\hline
\end{tabular}

\section{Streamlines pattern}

The streamlines around cylinder are compared between base fluid and nanofluid $(\varphi=0.05)$ in figure 2 at Reynolds number of 20 and 40 at UHF B.C. For high Reynolds number, the recirculation bubble becomes big and strong at the downstream side of the cylinder for both base fluid and nanofluid. However, in nanofluid the center of bubbles is slightly pushed away from the surface of the cylinder comparing with base fluid.

\section{Isotherm patterns}

The isotherms profiles around the rotating cylinder for Reynolds number of 40 for UHF B.C are compared between base fluid and nanofluid $(\varphi=0.05)$ in Figure 3. Clearly, the temperature distribution contours for base fluid are overlaid with that for nanofluid. This can be explained as the addition of solid particles to the base fluid increases the Reynolds number of nanofluid. Hence, a higher capacity of transferring the heat from the cylinder. It is obvious from Figure 3 that the isotherms have maximum density close to the front surface of the cylinder; this indicates high values of the local Nusselt number near the front stagnation point on the front surface as compared to other points on the cylinder surface. 


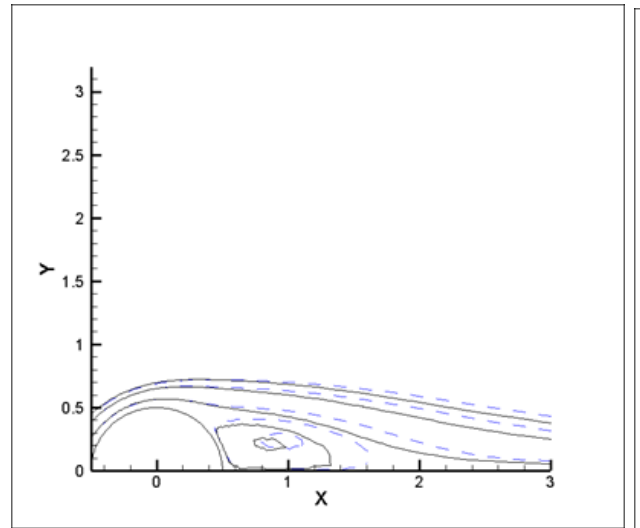

(a)

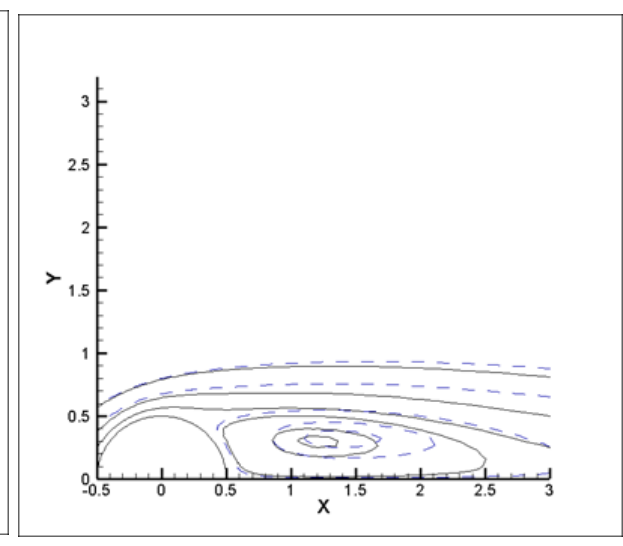

(b)

Fig. 2. Streamlines contours for the flow around the cylinder (solid line refers to base fluid and dashed line refers to nanofluid with solid volume fraction for UHF B.C. at (a) $R e=20$, (b) $R e=40$

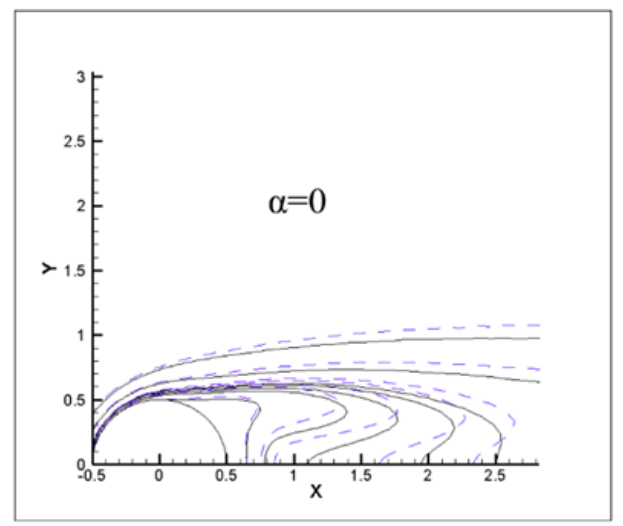

Fig. 3. Temperature contours for the flow around the cylinder (solid line refers to base fluid and dashed line refers to nanofluid with solid volume fraction 0.05) for UHF B.C. at $\operatorname{Re}=40$

\section{Local Nusselt number}

Figure 4 shows the variation of local Nusselt number $(\mathrm{Nu})$ on the surface of the cylinder with increase in $\operatorname{Re}$ for various volume fraction $\varphi$. When the solid concentration increases the thermal conductivity improves and consequently the local Nusselt number. Additionally, the thermal boundary layer is decreased by any increase in solid volume fraction. Therefore, the local Nusselt number is enhanced by any increasing in solid volume fraction $(\varphi)$. 

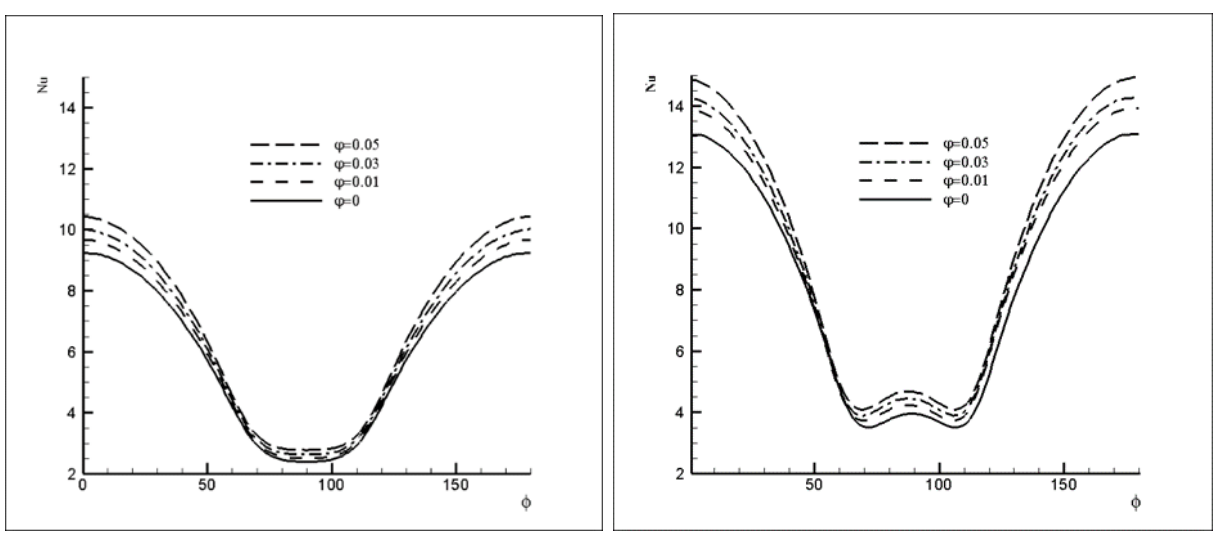

Fig. 4. Local Nusselt number variation at various solid volume fractions for varying values of Reynolds number and rotation rate, UHF B.C

On the other hand, for all Re, the variation of Nusselt found to be symmetrical at $\phi=180^{\circ}$. The value of the local $\mathrm{Nu}$ number is maximum on the front $(\phi=0)$ and minimum on the rear $\left(\phi=180^{\circ}\right)$ side of the cylinder. Also, at $\mathrm{Re}=40$, a kink is observed in the values of local Nusselt number. It can be explained on the basis that higher Reynolds number results in lager recirculation region.

Table 4 presents the difference due to adding solid nanoparticles fraction in $\mathrm{Nu}$. As expected, the table shows that the values of $\mathrm{Nu}_{\max }$ or $\mathrm{Nu}_{\min }$ is greater for UHF boundary condition.

Table 4. Local Nusselt number comparison

\begin{tabular}{ccccccc}
\hline & \multicolumn{6}{c}{$\mathrm{Re}=40$} \\
& $\mathrm{Nu}_{\max }$ & $\mathrm{Nu}_{\max }$ & Difference & $\mathrm{Nu}_{\min }$ & $\mathrm{Nu}_{\min }$ & Difference \\
\cline { 2 - 7 }$\varphi$ & $\mathrm{UHF}$ & $\mathrm{CWT}$ & UHF-CWT & UHF & $\mathrm{CWT}$ & UHF-CWT \\
\hline 0.01 & 13.9325 & 13.4567 & 0.4758 & 3.72545 & 2.51057 & 1.21488 \\
0.03 & 14.2648 & 14.1116 & 0.1532 & 3.89675 & 2.63901 & 1.25774 \\
0.05 & 14.9385 & 14.7632 & 0.1753 & 4.09028 & 2.07218 & 2.01810 \\
\hline
\end{tabular}

\section{Averaged Nusselt number}

The average Nusselt number variation is presented in Figure 5, for the solid volume fraction varying from 0 to 0.05 in the steady regime. This figure indicates that the averaged Nusselt number increases linearly with increasing solid volume fraction of nanoparticles $(\varphi)$ at different Reynold numbers. This can be explained as when Re number increases the inertia of flow increases thus increasing the heat transfer. The effect of Reynold numbers also increases with increase in volume fraction number (the Reynold and Prandtl numbers of nanofluids can be expressed as):

$$
\operatorname{Re}_{n f}=\frac{\rho_{n f}}{\rho_{f}} \frac{\mu_{f}}{\mu_{n f}} \operatorname{Re} ; \operatorname{Pr}_{n f}=\frac{\mu_{n f}}{\mu_{f}} \frac{C_{P, n f}}{C_{P, f}} \frac{k_{f}}{k_{n f}} \operatorname{Pr}
$$



number.

Further, the UHF boundary condition yields higher values of the average Nusselt
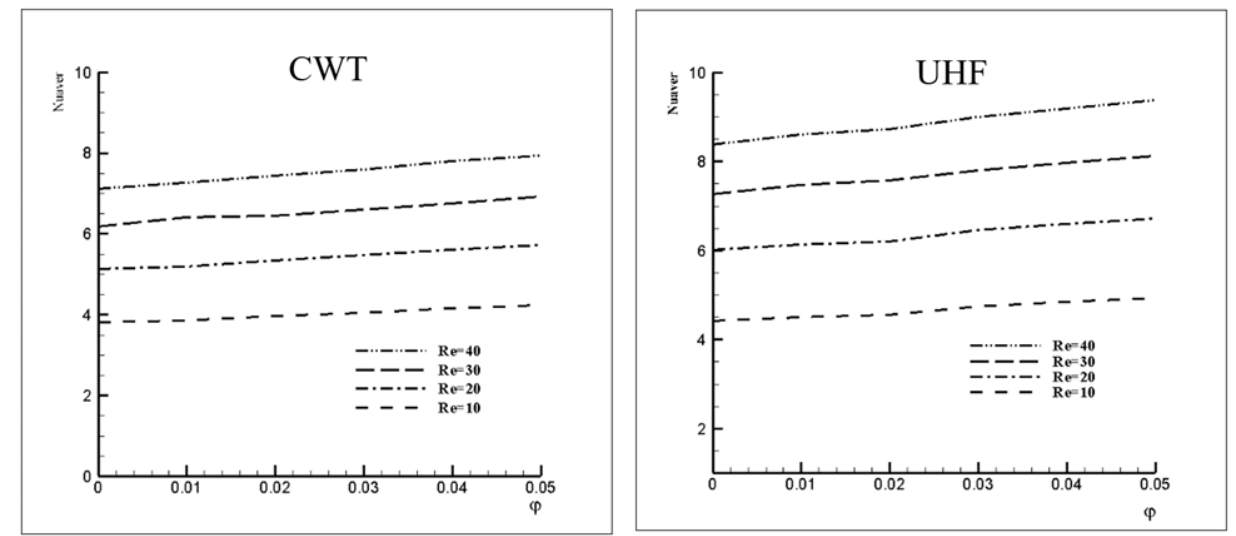

Fig. 5. Variation of average Nusselt number at various solid volume fractions for varying values of Reynold numbers

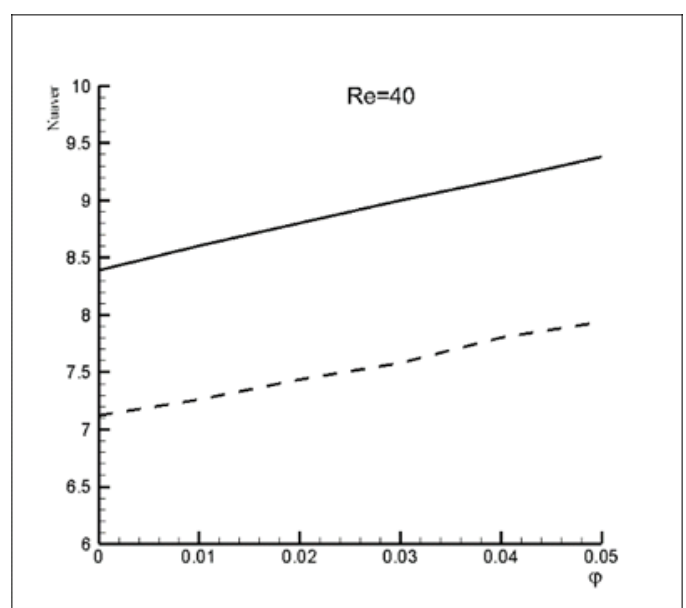

Fig. 6. Average Nusselt number variation for $0 \leq \varphi \leq 5$ at UHF (Solid lines) and CWT (Dashed lines)

\section{Conclusions}

The present study focuses on the unconfined laminar flow of nanofluid and heat transfer characteristics around a circular cylinder under the influence of both the thermal boundary conditions i.e. UHF and CWT in the steady regime. The illustrative streamline patterns and isotherm patterns are presented and examined for the above range of conditions. It was showed that at a given Reynolds number, local and average Nusselt numbers were enhanced by adding nanoparticles to base fluid. Moreover, the UHF boundary condition yields higher values of the average Nusselt number. 


\begin{tabular}{lll}
\multicolumn{2}{l}{ Nomenclature } & \\
$\mathrm{C}_{\mathrm{D}}$ & Drag coefficient & \\
$\mathrm{C}_{\mathrm{L}}$ & Lift coefficient & $\mathrm{N}$ \\
$\mathrm{D}$ & Drag force & $\mathrm{m}$ \\
$\mathrm{D}_{\mathrm{t}}$ & Diameter of the cylinder & $\mathrm{N}$ \\
$\mathrm{L}$ & Lift force & \\
$\mathrm{Nuaver}$ & Average Nusselt number & \\
$\mathrm{Nu}$ & Local Nusselt number & $\mathrm{N} / \mathrm{m}^{2}$ \\
$\mathrm{P}$ & Local pressure & \\
$\mathrm{Re}$ & Reynolds number & \\
$\mathrm{Pr}$ & Prandtl number & $\mathrm{K}$ \\
$\mathrm{T}_{\infty}$ & Free-surface temperature & $\mathrm{m} \cdot \mathrm{s}^{-1}$ \\
$\mathrm{U}_{\infty}$ & Free-stream velocity & $\mathrm{m} \cdot \mathrm{s}^{-1}$ \\
$\mathrm{u}$ & Stream-wise velocity & \\
$\mathrm{U}$ & Non-dimensional streamwise velocity $\left(=\mathrm{u} / \mathrm{U}_{\infty}\right)$ & $\mathrm{m} \cdot \mathrm{s}^{-1}$ \\
$\mathrm{v}$ & Cross-stream velocity & \\
$\mathrm{V}$ & Non-dimensional cross-stream velocity $(=\mathrm{v} / \mathrm{U} \infty)$ & \\
Greek symbols & \\
$\varphi$ & Nanoparticle volume fractions & \\
$\phi$ & Angular displacement from the front stagnation point & \\
$\theta$ & Non-dimensional temperature \\
$v$ & Kinematic viscosity &
\end{tabular}

\section{References}

[1] M. Hatami, M. Jafaryar, D. D. Ganji, M. Gorji-Bandpy: Int Commun Heat Mass Transfer, 57, 254-263.

[2] M. Hatami, D. D. Ganji, M. Gorji-Bandpy: Case Studies in Therm Eng, 4 (2014): 53-64.

[3] S. Sanitjai, R. J. Goldstein: Int J Heat Mass Transfer, 47 (2004) 4795-4805

[4] R. P. Bharti, R. P. Chhabra, V. Eswaran: Heat Mass Transfer, 43 (2007) 639-648

[5] M. Sufyan, S. Manzoor, N. A. Sheikh: Arabian J Sci Eng, 39 (2014) 8051-8063

[6] S. B. Paramane, A. Sharma: Int J Heat Mass Transfer, 52 (2009) 3205-3216.

[7] R. Bouakkaz, K. Talbi, Y. Khelil, F. Salhi, N. Belghar, M. Ouazizi: Thermophysics and Aeromechanics, 21(2014) 87-97.

[8] S. B. Paramane, A. Sharma: Int J Heat Mass Transfer, 53(2010) 4672-4683.

[9] H. C. Brinkman: J Chem Phys, 20 (1952) 571-581.

[10] H. Chang, C. S. Jwo, C. H. Lo, T. T. Tsung, M. J. Kao, H. M. Lin: Rev Adv Mater Sci, 10 (2005) 128-132.

[11] C. J. Ho, M. W. Chen, Z. W. Li: Int J Heat Mass Transfer, 51 (2008) 4506-4516.

[12] M. S. Valipour, A. Z. Ghadi: Int Commun Heat Mass Transfer, 38 (2011) 12961304.

[13] E. S. El-bashbeshy, T. G. Emam, M. S. Abdel-Wahed: Therm Sci, 19 (2015) 15911601. 
[14] Y. Khelili, A. Allali, R. Bouakkaz: Metall Mater Eng, 23 (2017) 83-97.

[15] V. Etminan-Farooji, E. Ebrahimnia-Bajestan, H. Niazmand, S. Wongwises: Int J Heat Mass Transfer, 55 (2012) 1475-1485.

[16] M. S. Valipour, R. Masoodi, S. Rashidi, M. Bovand, M. Mirhosseini: Therm Sci, 18 (2014) 1305-1314.

[17] W. Yu, S. U. S. Choi: J Nanopart Res, 5 (2003) 167-71.

[18] S. Kang, H. Choi, S. Lee: Phys Fluids, 11 (1999) 3312-3321.

[19] S. Mittal, B. Kumar: J Fluid Mech, 476 (2003) 303-334.

[20] J.C. Padrino, D. D. Joseph: J Fluid Mech, 557 (2006) 191-223.

[21] D. Stojkovic, M. Breuer, F. Durst: Phys Fluids, 14 (2002) 3160-3178. 